PROCEEDINGS OF THE

AMERICAN MATHEMATICAL SOCIETY

Volume 137, Number 4, April 2009, Pages 1371-1372

S 0002-9939(08)09617-2

Article electronically published on October 17, 2008

\title{
A SHORT PROOF OF PITT'S COMPACTNESS THEOREM
}

\author{
SYLVAIN DELPECH
}

(Communicated by Nigel J. Kalton)

\begin{abstract}
We give a short proof of Pitt's theorem that every bounded linear operator from $\ell_{p}$ or $c_{0}$ into $\ell_{q}$ is compact whenever $1 \leq q<p<\infty$.
\end{abstract}

A bounded linear operator between two Banach spaces $X$ and $Y$ is said to be compact if it maps the closed unit ball of $X$ into a relatively compact subset of $Y$.

Theorem (Pitt; see for example [1, p. 175). Let $1 \leq q<p \leq+\infty$, and put $X_{p}=\ell_{p}$ if $p<+\infty$ and $X_{\infty}=c_{0}$. Then every bounded linear operator from $X_{p}$ into $\ell_{q}$ is compact.

Proof. Let $T: X_{p} \rightarrow \ell_{q}$ be a norm-one operator. As $1<p$, the dual of $X_{p}$ is separable. Hence every bounded sequence in $X_{p}$ has a weakly Cauchy subsequence. Thus, for proving the compactness of $T$, it is enough to show that $T$ is weak-tonorm continuous. So, let us consider a weakly null sequence $\left(h_{n}\right)$ in $X_{p}$. We have to show that $\lim _{n \rightarrow \infty}\left\|T\left(h_{n}\right)\right\|=0$. We claim that

(1) for every $x \in c_{0}$ and for every weakly null sequence $\left(w_{n}\right)$ in $c_{0}$,

$$
\limsup _{n \rightarrow \infty}\left\|x+w_{n}\right\|=\max \left(\|x\|, \limsup _{n \rightarrow \infty}\left\|w_{n}\right\|\right) \text {, }
$$

(2) for every $x \in \ell_{r}, 1 \leq r<\infty$, and for every weakly null sequence $\left(w_{n}\right)$ in $\ell_{r}$,

$$
\limsup _{n \rightarrow \infty}\left\|x+w_{n}\right\|^{r}=\|x\|^{r}+\limsup _{n \rightarrow \infty}\left\|w_{n}\right\|^{r} .
$$

Indeed this is obvious when $x$ is finitely supported, because the coordinates of $\left(w_{n}\right)$ along the support of $x$ tend to 0 in norm. The general case is true by the density of finitely supported elements in $X_{p}$ and since the norm is a Lipschitzian function.

Fix $0<\varepsilon<1$. By definition of the norm of $T$, there exists $x_{\varepsilon} \in X_{p}$ such that $\left\|x_{\varepsilon}\right\|=1$ and $1-\varepsilon \leq\left\|T\left(x_{\varepsilon}\right)\right\| \leq 1$. Moreover, for all $n \in \mathbb{N}$ and for all $t>0$

$$
\left\|T\left(x_{\varepsilon}\right)+T\left(t h_{n}\right)\right\| \leq\left\|x_{\varepsilon}+t h_{n}\right\| .
$$

In the left-hand side of (0), we apply claim (2) in $\ell_{q}$, with $x=T\left(x_{\varepsilon}\right)$ and the weakly null sequence $\left(T\left(t h_{n}\right)\right)$.

First, assume $p<+\infty$. We apply claim (2) to the right-hand side of (0) with $r=p, x=x_{\varepsilon}$ and the weakly null sequence $\left(t h_{n}\right)$ to obtain

$$
\left[\left\|T\left(x_{\varepsilon}\right)\right\|^{q}+t^{q} \limsup _{n \rightarrow \infty}\left\|T\left(h_{n}\right)\right\|^{q}\right]^{\frac{1}{q}} \leq\left[\left\|x_{\varepsilon}\right\|^{p}+t^{p} \limsup _{n \rightarrow \infty}\left\|h_{n}\right\|^{p}\right]^{\frac{1}{p}} .
$$

Received by the editors February 6, 2008, and, in revised form, April 16, 2008.

2000 Mathematics Subject Classification. Primary 46B25.

Key words and phrases. $\ell_{p}$ space, $c_{0}$ space, compact operator.

(C)2008 American Mathematical Society Reverts to public domain 28 years from publication 
Recall that $\left\|x_{\varepsilon}\right\|=1,1-\varepsilon \leq\left\|T\left(x_{\varepsilon}\right)\right\| \leq 1$ and that $\left(h_{n}\right)$ is weakly convergent, thus bounded by some $M>0$. This gives

$$
\limsup _{n \rightarrow \infty}\left\|T\left(h_{n}\right)\right\|^{q} \leq \frac{1}{t^{q}}\left[\left(1+t^{p} M^{p}\right)^{q / p}-(1-\varepsilon)^{q}\right] .
$$

Taking $t=\varepsilon^{\frac{1}{p}}$ here, we get

$$
\limsup _{n \rightarrow \infty}\left\|T\left(h_{n}\right)\right\|^{q} \leq \frac{1}{\varepsilon^{q / p}}\left[1+\frac{q}{p} M^{p} \varepsilon-(1-q \varepsilon)+o(\varepsilon)\right] .
$$

Now, letting $\varepsilon \rightarrow 0$ here, we get that $\lim \sup _{n \rightarrow \infty}\left\|T\left(h_{n}\right)\right\|^{q} \leq 0$, and therefore the sequence $\left(T\left(h_{n}\right)\right)$ norm-converges to 0 .

Second, assume $p=+\infty$. We apply claim (1) to the right-hand side of (0) to obtain

$$
\limsup _{n \rightarrow \infty}\left\|T\left(h_{n}\right)\right\|^{q} \leq \frac{1}{t^{q}}\left[\max \left(1, t^{q} M^{q}\right)-(1-\varepsilon)^{q}\right] .
$$

Considering here any $0<\varepsilon<M^{-2 q}$ and then taking $t=\varepsilon^{\frac{1}{2 q}}$, we get that

$$
\limsup _{n \rightarrow \infty}\left\|T\left(h_{n}\right)\right\|^{q} \leq \frac{1}{\varepsilon^{1 / 2}}\left[1-(1-\varepsilon)^{q}\right] .
$$

Now, letting $\varepsilon \rightarrow 0$ here, we get as before that the sequence $\left(T\left(h_{n}\right)\right)$ norm-converges to 0 .

The framework of this paper was inspired by [2]. The proof given in [2], devoted to the case $p<+\infty$, uses Stegall's variational principle.

\section{REFERENCES}

[1] M. Fabian, P. Habala, P. Hájek, V. Montesinos Santalucía, J. Pelant and V. Zizler, Functional analysis and infinite-dimensional geometry, CMS Books in Mathematics, Springer-Verlag, New York, 2001. MR1831176 (2002f:46001)

[2] M. Fabian and V. Zizler, A "nonlinear" proof of Pitt's compactness theorem, Proc. Amer. Math. Soc. 131 (2003), 3693-3694. MR1998188 (2004g:46026)

Institut de Mathématiques de Bordeaux, UMR 5251, Université Bordeaux I, 351, Cours de la libération, 33405 Talence Cedex, France

E-mail address: sylvain.delpech@gmail.com 